\title{
Legg-Calvé-Perthes hastalığında kurtarma girişimleri
}

\author{
Salvage methods for Legg-Calvé-Perthes disease
}

\author{
Bartu Sarısözen \\ Uludağ Üniversitesi Tıp Fakültesi, Ortopedi ve Travmatoloji Anabilim Dalı, Bursa
}

\begin{abstract}
Femur başının henüz bariz bir deformite geliştirmediği, uygun seçilmiş Perthes hastalarında başın aşırı örtümü prensibine dayanan tedavi yöntemleri seçilebilirken, menteşeli abduksiyon gelişmiş ve buna bağlı abduksiyon hareketi kısıtlı veya instabilitesi olan, uyumu bozuk kalçalarda, tedavi yöntemleri bu sorunlara ancak kısmi çözümler getirebilir. Kurtarma girişimleri adı altında gruplanabilecek bu girişimlerden başlıcaları; valgus osteotomisi, femur boyun uzatma ve trokanterik kaydırma osteotomileri, şelf artroplastileri, Chiari osteotomisi ve femur başı küçültme girişimleridir. Valgus osteotomisi, gerek abduksiyon kısıtlılığı ve menteşeli abduksiyon varlığında gerekse kalça biyomekaniğinin düzeltilmesinde sağladığı yararlar nedeniyle, ön plana çıkan bir girişimdir. Perthes hastalığının, eklemdeki patolojik gelişimin geri döndürülemez olduğu nispeten geç dönemlerinde uygulanan bu cerrahi yöntemlerin başarısı, önemli ölçüde klinik bulguların ve morfolojik değişikliklerin iyi analiz edilerek doğru girişimin seçilmesine bağlıdır.
\end{abstract}

Anahtar sözcükler: Perthes hastalı̆̆ı; kurtarma girişimleri; valgus osteotomisi; şelf artroplastisi

\begin{abstract}
In appropriately chosen Perthes patients, treatment methods which are based on the principle of containment can be used when there is not an obvious femoral head deformity; whereas in patients with hinge or restricted abduction and joint instability or incongruency, treatment methods can only be partially useful. Common surgical methods which would fall under the category of salvage are namely valgus osteotomy, neck lengthening and trochanteric sliding ostoetomies, shelf arthroplasty, Chiari osteotomy and femoral head reduction. Valgus osteotomy is an outstanding method, generally useful in improving abduction motion, hinge abduction and biomechanics of the hip joint. The success of these methods utilized in relatively late stages of Perthes' disease, in which the pathological development of the joint is irreversible, highly depend on choosing the correct surgical method by better analyzing the clinical findings and morphologic changes in the hip.
\end{abstract}

Key words: Perthes disease; salvage surgery; valgus osteotomy; shelf arthroplasty erthes hastalığında sekel gelişimi açısından dört kritik dönem ayırt edilebilir:

1. Hastalığın başlangıcı (Perthes).

2. İyileşmenin sonu.

3. Çocukluk çağının sonu.

4. Hastalığın başlangıı (dejeneratif süreç).

Perthes hastalığında uygulanan tedavi yöntemlerinden olan kapsama veya aşırı örtüm girişimleri, (containment) ister konservatif isterse cerrahi tekniklerle uygulansınlar, zamanlama olarak erken evrede olmak zorundadır. ${ }^{[1-3]}$ Başka bir deyişle; aşırı örtüm girişimlerinin amacı, henüz biyolojik plastisite evresinde olan ve yeni iyileşmeye başlamış femur başının küresel şeklinin bozulmasını engellemek olmalıdır. Bu tanımın doğal sonucu olarak, aşırı örtüm girişimlerinin henüz başın küreselliği bozulmadan veya baş lateralinde çentiklenme (hinge abduction -menteşeli abduksiyon) gelişmeden yapılıyor olması gerekir. Bu dönem, birçok çocukta erken fragmantasyon dönemine denk gelir. Menteşeli abduksiyon ilk olarak A. Catterall tarafından tanımlanmıştır. ${ }^{[4]}$ Asetabulum lateral dudağı ve femur başının anterolateralindeki taşan kısım arasında bir tür sıkışma sendromu olarak da adlandırılabilecek bu durum, çocukların \%15-20'sinde görülür. ${ }^{[4]}$

Perthes hastalığında, konservatif veya cerrahi, aşırı örtüm girişimleri dışında femur başının şeklini korumaya yönelik etkinliği kanıtlanmış ve klasik bilgi

- İletişim adresi: Prof. Dr. Bartu Sarısözen, Uludağ Üniversitesi Tıp Fakültesi, Ortopedi ve Travmatoloji Anabilim Dalı, Bursa Tel: 0532 - 2570953 e-posta: bartu@uludag.edu.tr

- Geliș tarihi: 20 Șubat 2017 Kabul tarihi: 20 Șubat 2017 
haline gelmiş başkaca bir yöntem olmadığından; erken dönemin geçirildiği ve aşırı örtüm yöntemlerinin yersiz hale geldiği andan itibaren kalçanın uyumunu arttırmaya veya mekaniğini düzeltmeye yönelik yapılacak tedavi girişimlerinin tümünü "kurtarma" olarak tanımlamak doğru olur. Bu nedenle, Perthes hastalığında geç dönem kurtarma girişimleri, zaten bozuk olan kalça anatomisi ve mekaniğinde kısmi düzelme sağlayan işlemlerdir. Bir kısmı sekel olarak da adlandırılabilecek bu tür kalça sorunlarının başlıcaları;

a. Küreselliği bozulmuş, uyumsuz femur başı (koksa plana),

b. Lateralinde çentiği olan femur başı ve bazen beraberinde instabilite (hinge abduction -menteşeli abduksiyon),

c. Femur başı epifizindeki büyüme sorununa ve baştaki deformiteye bağlı boyun kısalığı (koksa breva),

d. Femur başı epifizindeki büyüme sorunu sürerken, büyük trokanterin normal gelişimine devam etmesi ve baş-boyun uyumunun bozulması (koksa vara),

e. Deforme femur başı epifizinin kötü mekanik stresi sonucunda hatalı gelişen, küreselliğini kaybetmiş ve "L" şeklini almış (çift kompartmanlı), lateralde baş örtümünü tam sağlayamayan deforme/displazik asetabulum varlığı, şeklinde sıralanabilir.

Yukarıda sıralanan sorunlar, çeşitli cerrahi girişimler ile onarılarak kalça eklemi daha uyumlu hale getirilebilir. Bu girişimleri eklem-dışı ve eklem-içi teknikler olarak gruplamak olanaklıdır. Kurtarma girişimleri, daha önce femur başının yapısını korumaya yönelik her hangi bir tedavi uygulanmamış çocuklarda olduğu kadar, bir girişim uygulanmış ancak buna rağmen kalça yapısının korunamadığı çocuklarda da tedavi seçeneği olabilir.

\section{EKLEMDIŞI CERRAHI GIRIŞiMLER}

Perthes hastalığında uygulanan eklem dışı kurtarma girişimlerinin başlıcaları; valgus, Chiari, ve trokanterik kaydırma osteotomileri ve şelf artroplastisidir. Bu girişimler, bazen birlikte veya diğer cerrahi girişimlerle birlikte de uygulanabilir.

\section{Valgus Osteotomisi}

Perthes hastalığında uygulanan valgus osteotomisi iki ana amaca yöneliktir. Bunlardan ilki, baş lateralindeki çentiklenmeye bağlı gelişen menteşeli abduksiyon hareketini tedavi etmektir. Valgus osteotomisinin bu nedenle uygulanması ile oldukça başarılı sonuç elde edilir. ${ }^{[5-9]}$ ikinci amaç ise femur üst ucundaki büyüme kusuruna bağlı bozulan trokanter - kalça eklem merkezi seviyesi ilişkisini ve dolayısıyla beraberindeki femur kısalığını ve eklem biyomekaniğini düzeltmeye yöneliktir.

Femur başı lateralinde yer alan ve abduksiyon sırasında menteşe etkisi yaratarak eklemin instabil olmasına ve abduksiyonun kısıtlanmasına yol açan çentik, valgus osteotomisi ile asetabular kenarın dışına kaydırılmış olur ve böylece, kalçanın normal abduksiyon hareket açısı içinde oluşan takılma önlenir (Şekil 1. A, B). Bu yöntemle, baştaki çentiğin abduksiyon sırasında asetabular labrumu ezmesi ve eklem dışına doğru iterek deforme etmesi de düzeltilmiş olur. Doğal olarak, bu girişimin hedefi baştaki deformiteyi düzeltmeye yönelik değil, kalçanın özellikle abduksiyon kısıtlılığını, ağrıyı, abduktor kaldıraç kolunu ve trendelenburg yürüyüşünü tedavi etmeye yöneliktir.

Valgus osteotomisi ile, başın inferomediyal kısmı dışa dönerek asetabulum tavanı karşısında yük taşıyan yüzey haline gelir. Bu nedenle, valgus osteotomisine karar verilmeden önce femur başı epifizinin mediyal bölümünün durumu açığa kavuşturulmalıdır. Buna yönelik olarak, ameliyat öncesinde kalçanın adduksiyon pozisyonundaki radyografileri incelenmeli ve mediyal epifiz - asetabulum uyumu değerlendirilmelidir (Şekil 2). Valgus osteotomisi uygulanmasının öncelikli şartlarından birisi, bu uyumun sağlanıyor olmasıdır. Aksi durumda, valgus osteotomisi ile düzelmesi beklenen eklem instabilitesi, hareket kısıtlılığı ve dejeneratif eklem hastalığı riski sorunları devam eder. Ameliyat öncesinde mediyal epifiz kısmının yük taşımaya elverişli olup olmadığı da değerlendirilmelidir. Valgus osteotomisi gerektiren kalçaların büyük çoğunluğu, başın bütününün veya büyük kısmının tutulduğu Catterall III-IV[10] veya Herring B-C ve $\mathrm{C}^{[11]}$ grubundadır. Doğal olarak, mediyal epifiz parçası da büyük olasılıkla etkilenmiş olacağından, valgus osteotomisi uygulanacak bir kalçanın zamanlama açısından erken dönemde ameliyat edilmesi doğru olmaz. Aksi takdirde, örneğin, erken fragmantasyon döneminde cerrahi yapılan bir kalçada mediyal epifiz yeni pozisyonunun gerektirdiği yük taşıma işlevini üstlenemez ve femur başında yeni deformiteler gelişebilir. ${ }^{[8]}$ Bu nedenle, valgus osteotomisi zamanlama olarak iyileşme dönemine girmiş kalçalarda uygulanmalıdır.

Valgus osteotomisinin çok erken dönemde yapılmasının sakıncası yanı sıra, fazla geciktirilmesi de soruna neden olabilir. Femur başındaki avasküler nekrozun iyileşerek baş epifizinin sağlam kemikle yer değiştirmesi, femurdaki deformite açısından önemli bir yeniden şekillenme potansiyelinin kalmadığını gösterir. Ancak, bu sırada asetabulumun gelişimi henüz 

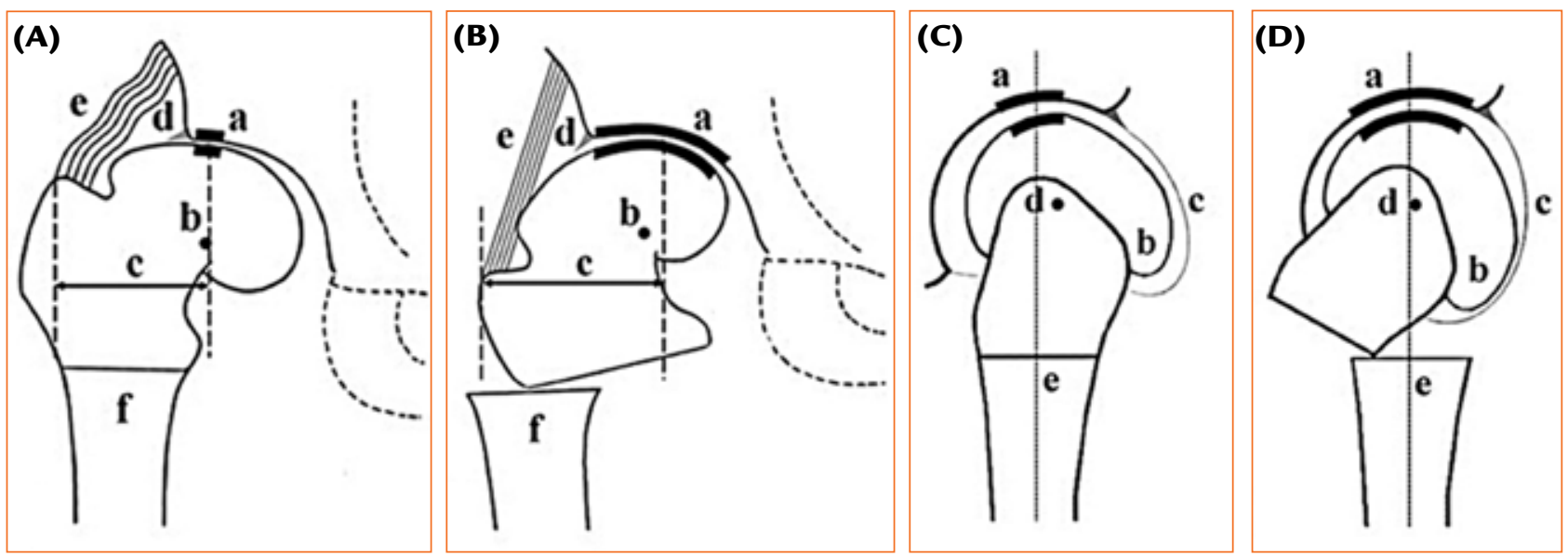

Şekil 1. A-D. Valgus-fleksiyon osteotomisinin (VFO) etkisinin şematik olarak gösterimi. A: VFO öncesinde kalçada subluksasyon ve eklemde uyumsuzluk, yük taşıyan yüzeyde daralma ve ön-arka planda asetabulum kenarında aşırı yüklenme var. B: VFO eklem uyumunu (a) ve yük binen yüzeyi arttırma, eklem merkezini (b) mediyalize etme, lateralde abduktor kaldıraç kolunu (c) uzatma, asetabular kenardaki yüklenmeyi (d) azaltma ve abduktor kas gerimini (e) arttırma amacını taşır. Femur distalinin, femur üst ucu ile ilişkisinin (f) bozulmaması için dışa kaydırılması gerekir. C: Yan planda VFO öncesinde kalçanın yük taşıma yüzeyi azalmış ve femur başının ön kısmı eklem dışına taşmıştır. D: Fleksiyon osteotomisi yük taşıyan yüzeyin uyumunu arttırır, makaslamayı (a) azaltır, femur başının dışa taşan kımını (b) asetabulum kenarından uzaklaştırır, kapsülün ön kısmını (c) gerginleştirir, ve rotasyon merkezini (d) arkaya iter. Distal femurun, femur üst ucu ile ilişkisinin (e) bozulmaması için sagittal planda öne kaydırılması gerekir. ${ }^{[6]}$
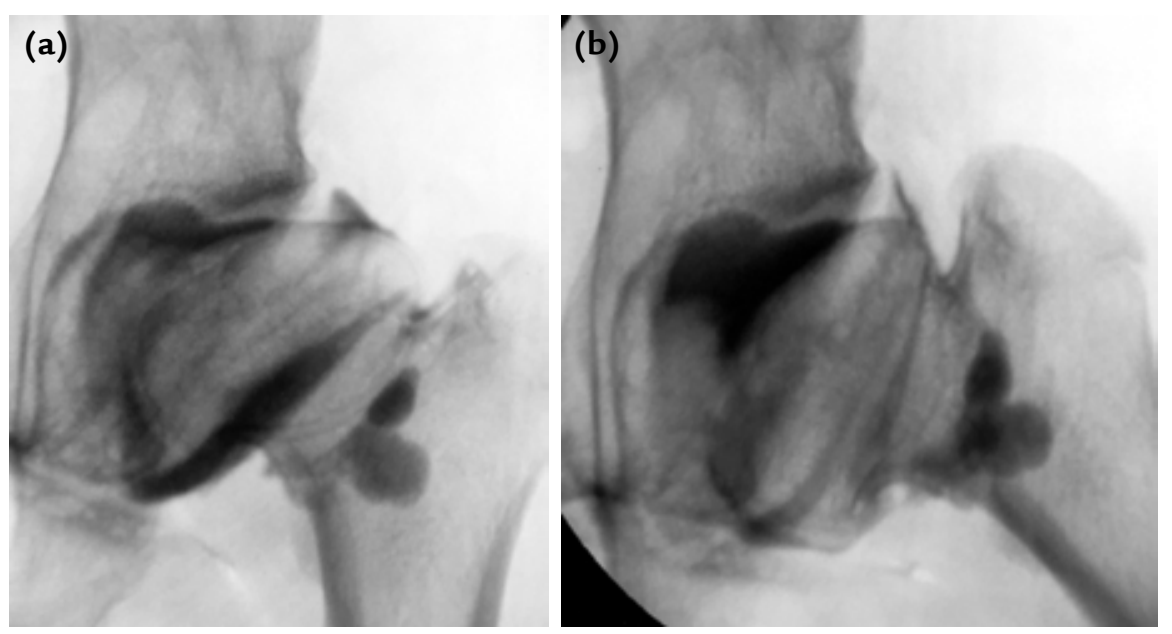

Şekil 2. a-e. Sağ kalçasında Perthes hastalığı nedeniyle osteotomi planlanan hastada ameliyat sırasında alınan artrografi görüntüleri: Nötral pozisyonda baş asetabulum uyumu bozuk. Başın yük taşıyan üst kısmında düzleşme izleniyor (a). Abduksiyonda eklem uyumu daha kötüleşiyor, femur başının mediyalinde boya göllenmesi var (b). Adduksiyonda eklem lateralindeki sıkışma rahatlıyor ve uyum artiyor (c). Valgus osteotomisinden sonra eklemin ön-arka (d) ve yan (e) görünümü. Eklemin yük taşıyan kısmında uyum daha iyi gözlenirken, baş merkezi - trokanter üst ucu seviyesi düzelmiş görülüyor. (Uludağ Üniversitesi Tıp Fakültesi arşivinden alınmıştır)
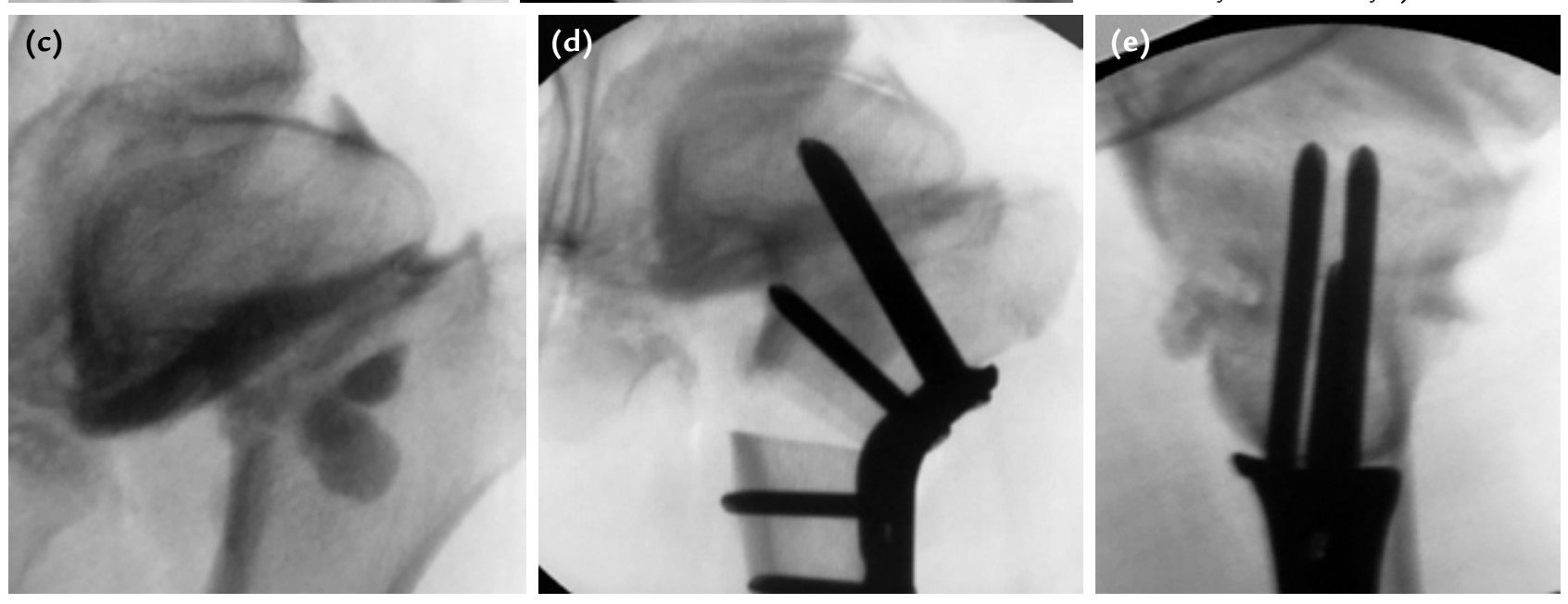
devam etmektedir. Valgus osteotomisi, her ne kadar bir kurtarma girişimi olsa da, çok geç uygulanması halinde, deforme femur başından etkilenen asetabulumda da kalıcı deformite olur. Triradiyat kıkırdağın henüz aktif olduğu ve asetabular gelişimin sürdüğü dönemde yapılacak bir osteotomi ile baş-asetabulum uyumu daha iyi hale getirilirse, asetabulumun da yeniden şekillenerek uyuma olumlu katkı yapması beklenir. Keza, valgus osteotomisi ile abduksiyon sırasında femur başı tarafından sıkıştırılmaktan kurtulan asetabular labrum da, kalan gelişim süresince asetabulum gelişimine katkı yapar. ${ }^{[12]} \mathrm{Bu}$ nedenle, valgus osteotomisinin zamanlaması ne çok erken, ne de çok geç olmalıdır.

Valgus osteotomisi uygulanmasının ana nedeni menteşeli abduksiyonun düzletilmesi ise, femur başındaki deformitenin cerrahi öncesinde iyi değerlendirilmesi gerekir. Ameliyat öncesi elde edilen radyografiler, manyetik rezonans veya bilgisayarlı tomografi görüntüleme teknikleri çok yararlı olmalarına rağmen, menteşeli abduksiyon dinamik bir deformite olduğundan, cerrahi sırasında yapılacak artrografik incelemenin yerini dolduramaz. Perthes hastalığında, yumuşayan femur başının dışarı taşma yönü lateral ve anteriordadır. Asetabulum dışına taşan bu kısmın daha sonra neden olduğu menteşe hareketi genel olarak abduksiyonda olmakla beraber, yerleşimi hastadan hastaya değişebilir. Bazı hastalarda, menteşe hareketinin en bariz gözlendiği an fleksiyonda veya bazen iç veya dış rotasyonda olabilir. Bu nedenle, taşan ve deforme olan kısmın hangi hareket açısında en tipik gözlendiğinin artrografi ile belirlenmesi, yapılacak osteotominin tipi açısından önem taşır. Örneğin, baştaki çentiklenme esas olarak öndeyse ve artrografik incelemede menteşe hareketi fleksiyonda daha belirginse, valgus-fleksiyon osteotomisi eklem uyumunu sağlamada daha başarılı olacaktır (Şekil 1. C, D). Baş-asetabulum uyumu adduksiyon - iç rotasyonda en iyi sağlanıyorsa veya kalçada fleksiyon deformitesi varsa, valgus-ekstansiyon osteotomisi uygun olacaktır. ${ }^{[13]}$

Valgus osteotomisinin, zaten bir kısmı asetabulum dışına taşmış olan femur başının örtümünü daha da azaltacağını varsayarak, çeşitli pelvik osteotomiler ile eş zamanlı uygulanması da önerilmiştir. Kim ve Wenger, valgus osteotomisini üçlü pelvik osteotomi ile beraber uygulayarak, eklemde oluşacak instabilite riskini önlediklerini belirtmişlerdir. ${ }^{[14]} \mathrm{Bu}$ görüşün karşısında, valgus osteotomisinin eş zamanlı pelvik bir osteotomi ile beraber uygulanmasının gereksiz olduğunu belirten görüşler de vardır. ${ }^{\left[{ }^{1,12}\right]}$ Valgus osteotomisi ile beraber en sık uygulanan örtüm arttırıcı girişimler; üçlü pelvik veya periasetabular osteotomiler, Chiari osteotomisi ve şelf ameliyatlarıdır.
Özetle;

1. Valgus osteotomisi, mediyal epifiz parçasını dışa kaydırarak yük taşıyan yüzey haline getirir ve menteşeli abduksiyonu düzeltir.

2. Ameliyattan önce femur başının anterolateralindeki çentiğin ve neden olduğu menteşeli abduksiyonun iyi değerlendirilmesi, osteotomi tipini belirleme açısından önemlidir; dinamik artrogram bu açıdan değerlidir.

3. Ameliyatın zamanlaması için, femur başının iyileşme dönemine geçmiş, ancak asetabular deformitenin henüz gelişmemiş olmasına dikkat edilmelidir.

\section{Femur Boyun Uzatma ve Trokanterik Kaydırma Osteotomileri}

Femur başındaki etkilenmenin fazla olduğu Perthes hastalarında, baş epifizindeki büyüme kusuruna karşın büyük trokanterin normal gelişimine devam etmesi sonucunda, femur başı-trokanter ilişkisi bozulur ve zamanla kısa bir boynu olan, varus görünümündeki bir femur ortaya çıkar. Femur başı - asetabulum uyumsuzluğuna ek olarak ortaya çıkan bu ikincil durum, kalçanın biyomekanik işlevini bozar ve klinik yakınmalara neden olur.

Koksa breva ile birlikte hastada ekstremite boy kısalığına ait bulgular da var ise, her iki soruna birden çözüm getiren girişim Morscher osteotomisidir. ${ }^{[15]}$ Uygulama tekniği açısından diğer osteotomilere göre daha kompleks olmasına karşın fonksiyonel sonuçlarının çok tatmin edici olduğunu bildiren çalışmalar vardır. ${ }^{[15,16]}$

Perthes hastalığının sekel döneminde büyük trokanterin distale kaydırılması ameliyatı, biyomekanik olarak kalçanın abduktor kaldıraç kolunu arttırmaya yönelik olarak uygulanabilir. ${ }^{[17,18]}$ Özellikle, alt ekstremitesinde kısalık gelişmemiş, ancak göreceli aşırı trokanterik büyüme sonucu femur boynu kısa hastalarda uygun bir girişim olabilir. Yine de, tek başına uygulanan bir girişim olarak, kalçadaki sorunları giderme açısından sağladığı katkı çok sınırlıdır. Asetabulum ve femur başındaki deformitelere ve eklem uyumsuzluğuna herhangi bir olumlu katkı yapmaması nedeniyle, etkisi abduktor kas gücünü ve varsa trendelenburg yürüyüşünü iyileştirmekten öteye gitmez. Trokanterik kaydırma girişimi, daha sıklıkla diğer cerrahi girişimlere ek olarak uygulanır. Özellikle, bir aşırı örtüm yöntemi olarak uygulanan varus osteotomisi sırasında, kalçanın biyomekaniğini rahatlatmak ve varus pozisyonunun ters etkilerini azaltmak amacıyla kombine edilir. Bir başka uygulanma yeri ise, femur başında güvenli çıkık 
oluşturularak osteokondroplasti veya baş küçültme girişimleri sırasında bu işlemlere eklenmesidir.[19] Trokanterik epifizyodez ile büyümenin yönlendirilmesi, trokanterik kaydırmaya bir alternatif olarak düşünülebilir. Uygun bir zamanlama ile yapılırsa, trokanterin göreceli olarak aşırı büyümesi önlenir ve gelecekteki bir osteotomiden kaçınılmış olur. ${ }^{[20]}$

Özetle;

1. İzole trokanterik kaydırma osteotomisi, boy kısalığı olmayan ancak femur boynu kısa hastalarda biyomekanik iyileşme sağlar.

2. Femur boynunu uzatmaya veya göreceli trokanterik aşırı büyümeyi düzeltmeye yönelik girişimlerin baş-asetabulum uyumsuzluğuna olumlu bir katkıları yoktur.

\section{Şelf Artroplastisi}

Perthes hastalığında uygulanan şelf artroplastisinin iki temel amacı vardır. Bunlardan ilki, asetabulumun lateraldeki kenarını dışa uzatarak menteşeli abduksiyonu ortadan kaldırmak ve taşan femur başı üzerindeki örtümü arttırmaktır. İkincisi ise, eklem dışına taşarak sublukse olma eğilimindeki femur başı üzerinde bir çatı oluşturarak eklemin stabilitesini arttırmaktır. Oluşturulan çatı eklem kıkırdağı yerine fibrokartilaj tipinde yapay bir eklem yüzü sağladığından, fizyolojik bir eklem çatısı olmaktan uzaktır. Şelf girişimlerinde, asetabulumun pozisyon ve yöneliminde değişiklik olmaz. Bu durum, daha karmaşık girişimler olan pelvik ostotomilerle karşılaştırıldığında teknik bir avantaj gibi görünse de, temelde kalçanın biyomekanik işlevinde bir değişiklik oluşturmaması nedeniyle, şelf artroplastisi bir aşırı örtüm ameliyatı değil, bir kurtarma girişimi olarak düşünülmelidir. Bu özellikleri nedeniyle, Chiari osteotomisi ile benzerlik gösterir.

Çeşitli çalışmalarda, şelf girişimlerinin Perthes hastalığındaki endikasyonları konusunda farklı görüşler olsa da, genel olarak etkinliği üzerinde görüş birliği vardır. ${ }^{[21-25]}$ Görüş farklılığının temel nedeni, menteşeli abduksiyon varlığında uygulanması ile ilgilidir. Menteşeli abduksiyon varlığında şelf girişimi uygulanmaması gerektiğini savunanlar olduğu gibi ${ }^{[22-24,26]}$, şelf ameliyatı sonrasında ağrı yakınmalarında ciddi düzelme ve eklem uyumunda olumlu gelişme saptadığını belirten araştırıcılar da vardır. ${ }^{[21,25]}$

Şelf artroplastisi, büyük sıklıkla Staheli ve Chew tarafından tanımlandığı şekliyle uygulanır. ${ }^{[27]}$ iliak kanattan alınan şerit şeklindeki kemik greftleri, asetabular dudağın hemen üzerinde oluşturulan bir yarığa, başın anterior ve lateralini örtecek şekilde yerleştirilir.
Gelişmesi devam eden kalçada bu tekniğin uygulanması sırasında, asetabulumun lateral büyüme kıkırdağında zedelenme riski olabileceği unutulmamalıdır. Çeşitli çalışmalarda, bu riske dikkat edilerek yapılan şelf ameliyatlarından sonra asetabulum dış kenarının gelişmeye devam ettiği, hatta gelişiminin uyarıldığı da belirtilmiştir. ${ }^{[23]}$

Özetle;

1. Asetabular çatıya ek destek sağlamakla beraber, eklem yüzünde gerçek bir biyomekanik etki yaratmaz.

2. Menteşeli abduksiyon varlığında endikasyonu net değildir.

\section{Chiari Osteotomisi}

Femur başı ve asetabulum arasındaki uyumun bozulduğu, femur başı üzerindeki örtümün yetersiz kaldığı, instabil veya menteşeli abduksiyon hareketi olan eklemlerde, Chiari osteotomisi bir seçenek olarak öne çıkar. Chiari K tarafından 1950 yılında tanımlanan ve bugün için hala geçerliliğini koruyan bu girişim, hangi kalça sorununda uygulanırsa uygulansın, sorundan bağımsız olarak gerçek bir kurtarma girişimidir. ${ }^{[28]}$ Amaç, femur başının küresel yapısını ve eklem uyumunu korumak değil, zaten yük taşıyan yüzeyi küçülmüş ve bu nedenle belirgin dejeneratif artrit eğilimi olan eklemin yük taşıma yüzeyini arttırmak ve osteoartiti geciktirmektir. Chiari osteotomisi, başta gelişimsel kalça displazisi olmak üzere, sublukse kalçalarda ve ağrılı çocuk ve erişkin kalçalarında kurtarma ameliyatı olarak ün yapmıştır. Gerek eklem uyumunun bozukluğu (Stulberg III, $\mathrm{IV}^{[29]}$ ) gerekse Perthes hastalığının ileri evrede olması nedeniyle, varus osteotomisi veya pelvik osteotomilerin kontrendike olduğu kalçalarda femur başının örtümünü arttırmak açısından en ön plana çıkan girişim, Chiari osteotomisidir.

Cerrahi teknikte hata yapılması, diğer osteotomiler gibi Chiari osteotomisinde de sonucu olumsuz etkiler. Özellikle osteotomi hattının asetabular eklem dış kenarının hemen üzerinden geçmemesi veya yöneliminin hafif yukarıya olmaması, istenen örtümün elde edilememesi ile sonuçlanır. ${ }^{30]}$

Bunun yanında, küçük çocuklarda uygulanması halinde, ameliyattan sonraki büyüme döneminde merkez-kenar açısının giderek küçüldüğünü bildiren araştırıcılar vardır. ${ }^{[31]}$

Chiari osteotomisinin olumsuz yönlerinden birisi, zaten femur boynunda göreceli kısalık nedeniyle, biyomekaniği bozuk kalçanın biraz daha yukarı kayarak daha da olumsuz etkilenebilmesidir. 


\section{Özetle;}

1. Chiari osteotomisi, eklem uyumu bozuk ve sekel dönemine geçmiş çocuklarda, asetabular displazi, femur başının yük taşıyan temas yüzeyinin yetersizliği, subluksasyon veya ağrı gibi sorunları düzeltmede yararlıdır.

2. Ameliyatın başarısı, osteotominin yeri ve yönelimi ile ilişkilidir.

\section{EKLEMIÇi CERRAHI GIRIŞiMLER}

Osteokondroplastiler, baş küçültme girişimleri ve femoroasetabular sıkışma sendromuna yönelik girişimler bu grupta sayılabilir. Özellikle Stulberg I ve II kategorisinde, uyum sorunu olmayan bazı Perthes sekeli kalçalar, femoroasetabular sıkışma sendromu ve labral patolojiler nedeniyle yine de dejeneratif hastalık riski taşır. Bu hastalarda, femur başı ile asetabulum arasındaki sıkışmanın ve labral patolojilerin düzeltilmesi, osteoartrit riskinin en aza inmesini ve eklem uyumunun devamını sağlar. Başlıca, artroskopik girişimler ve güvenli eklem dislokasyonu ile yapılan cerrahi tekniklerden oluşan bu yöntemler tekrar sağlıklı bir ekleme dönülmesini sağladıklarından, bir kurtarma girişimi sayılmaz. Bu nedenle, bu bölümde bahsi geçen bu girişimler anlatılmamıştır.

illeri derecede deforme femur başının morfolojisini iyileştirmeye yönelik olarak yapılan baş küçültme girişimleri ise kurtarma girişimleridir. Bu gruptan sayabileceğimiz, femur başının asetabulumdan dışarı taşan bölümlerinin eksize edilmesi işleminin (cheilectomy -kısmi baş rezeksiyonu), eski bir geçmişe dayanmasına karşın, klinik başarısı çok düşüktür ve günümüzde önerilmemektedir. ${ }^{[32]}$ Bugün, femur başının bu teknikle şekillendirilmesi terk edilmiş, bunun yerine artroskopik olarak veya gerektiği durumda güvenli çıkık oluşturularak femur başına osteokondroplasti uygulanması yaygınlaşmıştır.

Ancak, küresel şekli ciddi derecede bozulmuş femur başından eklem dışına taşan veya sıkışma yaratan kısımların ve ileri derecede deforme, merkezde gelişen nekroz nedeniyle eyer şeklini almış femur başında ortadaki dejenere kısmın çıkarılması, R. Ganz ve arkadaşları tarafından tanımlanmış bir baş küçültme yöntemidir ${ }^{33}$. Teknik zorluğu ve femur başı dolaşımı üzerinde oluşturduğu risk nedeniyle standart bir girişim haline gelmemesine ve uzun dönem klinik ve radyolojik sonuçları ile ilgili yeterli bilimsel sonuç olmamasına karşın, uygun seçilmiş hastalarda, baş deformitesini azaltarak eklem uyumunu arttırır ve uzun dönemde eklemde dejeneratif artrit gelişimini geciktirir. ${ }^{[33-35]}$

\section{KAYNAKLAR}

1. Joseph B, Varghese G, Mulpuri K, Narasimha Rao K, Nair NS. Natural evolution of Perthes disease: a study of 610 children under 12 years of age at disease onset. J Pediatr Orthop 2003;23(5):590-600.

2. Axer A, Gershuni DH, Hendel D, Mirovski Y. Indications for femoral osteotomy in Legg-Calvé-Perthes disease. Clin Orthop Relat Res 1980;(150):78-87.

3. Hoikka V, Poussa M, Yrjönen T, Osterman K. Intertrochanteric varus osteotomy for Perthes' disease. Radiographic changes after 2-16-year follow-up of 126 hips. Acta Orthop Scand 1991;62(6):549-53.

4. Catterall A. Legg-Calvé-Perthes syndrome. Clin Orthop Relat Res $1981 ;(158): 41-52$.

5. Choi IH, Yoo WJ, Cho TJ, Moon HJ. The role of valgus osteotomy in LCPD. J Pediatr Orthop 2011;31(2 Suppl):S217-22. Crossref

6. Kim HT, Gu JK, Bae SH, Jang JH, Lee JS. Does valgus femoral osteotomy improve femoral head roundness in severe Legg-Calvé-Perthes disease? Clin Orthop Relat Res 2013;471(3):1021-7. Crossref

7. Quain S, Catterall A. Hinge abduction of the hip. Diagnosis and treatment. J Bone Joint Surg Br 1986;68(1):61-4.

8. Bankes MJ, Catterall A, Hashemi-Nejad A. Valgus extension osteotomy for 'hinge abduction' in Perthes' disease. Results at maturity and factors influencing the radiological outcome. J Bone Joint Surg Br 2000;82(4):548-54.

9. Yoo WJ, Choi IH, Moon HJ, Chang S, Cho TJ, Choi YH, Park MS, Chung CY. Valgus femoral osteotomy for noncontainable Perthes hips: prognostic factors of remodeling. J Pediatr Orthop 2013;33(6):650-5. Crossref

10. Catterall $A$. The natural history of Perthes' disease. J Bone Joint Surg Br 1971;53(1):37-53.

11. Herring JA, Kim HT, Browne R. Legg-Calvé-Perthes disease. Part I. Classification of radiographs with use of the modified lateral pillar and Stulberg classifications. J Bone Joint Surg Am 2004;86-A(10):2103-20.

12. Yoo WJ, Choi IH, Chung CY, Cho TJ, Kim HY. Valgus femoral osteotomy for hinge abduction in Perthes' disease. Decision-making and outcomes. J Bone Joint Surg $\mathrm{Br}$ 2004;86(5):726-30.

13. Raney EM, Grogan DP, Hurley ME, Ogden MJ. The role of proximal femoral valgus osteotomy in Legg-Calvé-Perthes disease. Orthopedics 2002;25(5):513-7.

14. Kim HT, Wenger DR. Surgical correction of "functional retroversion" and "functional coxa vara" in late LeggCalvé-Perthes disease and epiphyseal dysplasia: correction of deformity defined by new imaging modalities. J Pediatr Orthop 1997;17(2):247-54.

15. Hasler CC, Morscher EW. Femoral neck lengthening osteotomy after growth disturbance of the proximal femur. J Pediatr Orthop B 1999;8(4):271-5.

16. Standard SC. Treatment of coxa brevis. Orthop Clin North Am 2011;42(3):373-87. Crossref

17. Macnicol MF, Makris D. Distal transfer of the greater trochanter. J Bone Joint Surg Br 1991;73(5):838-41.

18. Givon U, Schindler A, Ganel A, Levy O. Distal transfer of the greater trochanter revisited: long-term follow-up of nine hips. J Pediatr Orthop 1995;15(3):346-8.

19. Anderson LA, Erickson JA, Severson EP, Peters CL. Sequelae of Perthes disease: treatment with surgical hip dislocation and relative femoral neck lengthening. J Pediatr Orthop 2010;30(8):758-66. Crossref 
20. Stevens PM, Anderson LA, Gililland JM, Novais E. Guided growth of the trochanteric apophysis combined with soft tissue release for Legg-Calvé-Perthes disease. Strategies Trauma Limb Reconstr 2014;9(1):37-43. Crossref

21. Kruse RW, Guille JT, Bowen JR. Shelf arthroplasty in patients who have Legg-Calvé-Perthes disease. A study of long-term results. J Bone Joint Surg Am 1991;73(9):1338-47.

22. Bursalı A, Erkula G. Lateral shelf acetabuloplasty in the treatment of Legg-Calvé-Perthes disease. J Pediatr Orthop B 2004;13(3):150-2.

23. Daly K, Bruce C, Catterall A. Lateral shelf acetabuloplasty in Perthes' disease. A review of the end of growth. J Bone Joint Surg Br 1999;81(3):380-4.

24. Domzalski ME, Glutting J, Bowen JR, Littleton AG. Lateral acetabular growth stimulation following a labral support procedure in Legg-Calvé-Perthes disease. J Bone Joint Surg Am 2006;88(7):1458-66.

25. Freeman RT, Wainwright AM, Theologis TN, Benson MK. The outcome of patients with hinge abduction in severe Perthes disease treated by shelf acetabuloplasty. J Pediatr Orthop 2008;28(6):619-25. Crossref

26. Yoo WJ, Choi IH, Cho TJ, Chung CY, Shin YW, Shin SJ. Shelf acetabuloplasty for children with Perthes' disease and reducible subluxation of the hip: prognostic factors related to hip remodelling. J Bone Joint Surg Br 2009;91(10):1383-7. Crossref

27. Staheli LT, Chew DE. Slotted acetabular augmentation in childhood and adolescence. J Pediatr Orthop 1992;12(5):569-80.
28. Chiari K. Medial displacement osteotomy of the pelvis. Clin Orthop Relat Res 1974;(98):55-71.

29. Stulberg SD, Cooperman DR, Wallensten R. The natural history of Legg-Calvé-Perthes disease. J Bone Joint Surg Am 1981;63(7):1095-108.

30. Calvért PT, August AC, Albert JS, Kemp HB, Catterall A. The Chiari pelvic osteotomy. A review of the long-term results. J Bone Joint Surg Br 1987;69(4):551-5.

31. Cahuzac JP, Onimus M, Trottmann F, Clement JL, Laurain JM, Lebarbier P. Chiari pelvic osteotomy in Perthes disease. J Pediatr Orthop 1990;10(2):163-6.

32. Rowe SM, Jung ST, Cheon SY, Choi J, Kang KD, Kim KH. Outcome of cheilectomy in Legg-Calvé-Perthes disease: minimum 25-year follow-up of five patients. J Pediatr Orthop 2006;26(2):204-10.

33. Leunig M, Ganz R. Relative neck lengthening and intracapital osteotomy for severe Perthes and Perthes-like deformities. Bull NYU Hosp Jt Dis 2011;69(Suppl 1):S62-7.

34. Paley D. The treatment of femoral head deformity and coxa magna by the Ganz femoral head reduction osteotomy. Orthop Clin North Am 2011;42(3):389-99. Crossref

35. Siebenrock KA, Anwander $H$, Zurmühle CA, Tannast $M$, Slongo T, Steppacher SD. Head reduction osteotomy with additional containment surgery improves sphericity and containment and reduces pain in Legg-Calvé-Perthes disease. Clin Orthop Relat Res 2015;473(4):1274-83. Crossref 